\title{
ERPs during continuous recognition memory for words and pictures
}

\author{
STEVEN BERMAN, DAVID FRIEDMAN, and MARGARET CRAMER \\ New York State Psychiatric Institute, New York, New York
}

\begin{abstract}
Event-related brain potentials (ERPs) and performance measures were recorded from young adults during continuous recognition memory for word or picture representations of the same concepts. Subjects made speeded choice responses as to whether the item was "new" or "old," with "old" items repeated after lags of 2,8 , or 32 intervening stimuli following their first presentation. Longer lags were associated with poorer performance in words but not in pictures. A sequence of endogenous ERP components was responsive to repetition (old vs. new) and stimulus modality (pictures vs. words), and differed in scalp distribution as a function of both variables. The data suggest that multiple brain generators contribute to ERP repetition effects and support theoretical models that hypothesize processing differences between words and pictures.
\end{abstract}

In conjunction with behavioral measures, the recording of event-related brain potentials (ERPs) has been shown to be a useful tool for mental chronometry, enabling more direct mapping of theoretical concepts derived from cognitive psychology onto nervous system activity. We here report on the behavioral and ERP correlates of continuous recognition memory, focusing on the effects of stimulus modality (word vs. picture presentation of a concept), item repetition (old vs. new), and lag (i.e., the number of intervening items between first and second presentation).

It is currently unclear to what extent different brain systems are involved in the processing of words and pictures. The empirical finding that memory for pictures is usually superior to memory for words has been hypothesized to result from a more distinctive sensory code for pictures (Nelson, 1979) or because pictures are more likely than words to be encoded by dual verbal and nonverbal coding systems (Paivio, 1986). To the extent that word and picture memory show similar correlations with experimental variables, support can be claimed for theoretical positions that postulate amodal cognition or minimal differences between the processes used to encode and retrieve word and picture stimuli. Since differences in scalp distribution between conditions are usually cited as evidence in support of differences in the locus of intracranial generation, finding such word-picture differences might be indicative of more separable brain and information-processing systems for words and pictures.

Repetition effects may represent operations primarily associated with the first presentation, such as initial schema activation, which need not be as detailed on second presentation, or retrieval-related processes, such as

This research was supported in part by Grant HD14959 and Research Scientist Development Award K02 MH00510 (D. Friedman). Reprint requests may be addressed to Steven Berman, 2415 Washington, Santa Monica, CA 90403. context updating (see Donchin \& Coles, 1988), that might occur primarily to the item's second presentation. A number of investigators (the majority using word stimuli) have reported that, from about 300 to $600 \mathrm{msec}$ poststimulus, ERPs are more negative for initial presentations of to-beremembered items than are ERPs for second presentations of the same items (Friedman, 1990a, 1990b; Neville, Kutas, Chesney, \& Schmidt, 1986). There is some evidence that repetition affects more than one ERP component (e.g., Rugg \& Nagy, 1989; Smith \& Halgren, 1989). However, a formal test of the differentiation of these ERP processes based on scalp distribution has not been attempted.

The manipulation of lag allows for exploration of memorial decay. A repetition at a lag of 2 presumably tests retrieval of information from primary memory, which is characterized by limited capacity and fast decay (Waugh \& Norman, 1965). Correct response to a repetition after a longer lag presumably depends on information being retrieved from a more stable memory store. Recent work with word stimuli in our laboratory (Friedman, 1990b) showed a systematic decrement in behavioral performance with longer lags, with a trend towards an effect of lag on the ERPs. In another study using pictorial stimuli (Friedman, 1990a), performance at short and long lags was equivalent, with no ERP lag effects. This was interpreted as being due to the greater durability of pictorial memory. The current study was designed to directly compare and contrast the effects of lag on the ERP and behavioral measures of picture and word processing.

\section{METHOD}

Subjects

The subjects were 9 females and 6 males between the ages of 22 and 31 years $($ mean $=25.7, S D=2.4)$.

Stimuli, Procedures, and EEG Recording Methods

The stimuli were 324 line drawings and their lexical equivalents (Berman, Friedman, Hamberger, \& Snodgrass, 1989). Eight sets of 27 experimental items were randomly selected and assigned to eight blocks, 
such that each block had nine items repeated at each of three randomly ordered lags $(2,8$, or 32 items intervening between the first and second presentations). The remaining 108 pictures were used as foils (nonrepeating), and 108 different pictureable concepts were selected as word foils from the Kucera and Francis (1967) word count. Four sets of word foils and four sets of picture foils ( 27 per set) were used to fill in the eight blocks. Each block consisted of either 81 words or 81 pictures. Although 16 blocks were created by using the lexical equivalents of the experimental pictures (Word Blocks 1-8; Picture Blocks 1-8), each subject was assigned either Word Blocks 1-4 and Picture Blocks 5-8 or the remaining eight blocks presented in an ABBAABBA design. Block 1 foils were reused in Block 5 for both words and pictures, Block 2 foils were reused in Block 6, and so on. This design allowed each subject to see all 216 foils and all 216 experimental items. While there were separate sets of 108 word and picture foils, the 216 experimental items were prepared in both forms and viewed by half of the subjects as a word and by the other half as a picture (counterbalanced across subjects).

Stimuli were presented for $300 \mathrm{msec}$ on a Macintosh computer (interstimulus interval $=2 \mathrm{sec}$ ). The horizontal and vertical visual angles subtended by the pictures ranged, respectively, from $3.3^{\circ} \times 5.9^{\circ}$ for the largest picture to $2.3^{\circ} \times 2.9^{\circ}$ for the smallest picture. The horizontal visual angle for words varied from $5.6^{\circ}$ to $1^{\circ}$, with a vertical angle of $0.5^{\circ}$.

The subjects made speeded "new" (not seen previously in the block) or "old" (seen previously in the block) choice responses by pressing one of two buttons. The buttons assigned to the two hands were counterbalanced across subjects. Only reaction times (RTs) between 200 and 2,200 msec poststimulus were considered correct responses. Practice blocks of 18 unused words and pictures were administered prior to data collection.

EEG (10 sec time constant; $30 \mathrm{~Hz}$ upper cutoff) was recorded with a Beckman R612 polygraph and an Electro-Cap from $\mathrm{Fz}, \mathrm{Cz}, \mathrm{Pz}, \mathrm{Oz}$, T3, T4; vertical and horizontal EOGs were recorded from electrodes on the supraorbital ridge and outer canthus of the right eye, respectively. All channels were referred to nosetip. Data acquisition and stimulus presentation were controlled by a PDP $11 / 03$ computer, which digitized EEG and EOG at 10 -msec intervals for a 300 -msec prestimulus interval and a 1,700-msec poststimulus interval. Digitized records and behavioral data were stored on nine-track digital tape for offline analyses. Trials containing eye artifact were eliminated from the averages.

ERP deflections were visually identified as time windows in the individual subject and grand mean data (correct responses only) and were measured as averaged voltages within each latency window, relative to the 300 -msec prestimulus baseline.

All $F$ ratios were tested using degrees of freedom computed from application of the Greenhouse-Geisser correction. To assess differences in scalp distribution between conditions or ERP components, we normalized all amplitude data involved in significant electrode site interactions (to eliminate amplitude differences between conditions or components) and reanalyzed the data to assess shape across the scalp midline (see McCarthy \& Wood, 1985). Thus, a significant interaction with electrode site after normalization indicates different scalp distributions for the different conditions or components.

Because pictures and words differ in physical configuration, 5 additional subjects saw a modification of the procedure, in which half of the word blocks were presented in a smaller, 12-point, font than the one described above (average visual angle $=1.2^{\circ}$ horizontal by $0.2^{\circ}$ vertical) and the other words were presented with a larger, 24-point, font using white letters presented in a black square $\left(2.6^{\circ} \times 0.8^{\circ}\right)$. All recording procedures were similar to those described above, except that a larger array of electrodes was sampled $(\mathrm{Fz}, \mathrm{Cz}, \mathrm{Pz}, \mathrm{F} 7, \mathrm{~F} 8, \mathrm{~T} 3, \mathrm{~T} 4$, $\mathrm{T} 5, \mathrm{~T} 6, \mathrm{O} 1, \mathrm{O} 2$ ). If an ERP difference between pictures and words is produced by differences in physical parameters, such as brightness or retinal area stimulated, then the ERPs elicited using the large font should differ in the same way from those elicited using the small font.

\section{RESULTS AND DISCUSSION}

\section{Picture Versus Word Processing}

As can be seen in Table 1, RTs to "new" items were faster than RTs to "old" items $[F(1,14)=17.6, p<$ $.001]$. A main effect of lag on $\mathrm{RT}[F(1,21)=3.9, p<.05]$ was modified by an interaction with stimulus modality $[F(2,28)=5.0, p<.02]$. Multiple comparisons showed that words repeated after a lag of 32 produced longer RTs than did words repeated after lags of 2 or 8 . In contrast, picture RTs were faster after a lag of 8 than after lags of 2 and 32. The faster RTs to pictures after a lag of 8 , relative to a lag of 2 , replicates a recent result using picture slides (Friedman, 1990a), and has since appeared in a third sample for pictures but not for words (Berman, Friedman, \& Cramer, 1990). While the RT increment from Lag 2 to Lag 32 in words, but not pictures, supports the idea that pictures are not held in a capacitylimited primary store (as words are thought to be), we have no explanation for the superior picture performance after a lag of 8 items. However, it seems likely that this also represents a difference in the way words and pictures are processed.

Figure 1 presents the grand mean ERPs elicited by pictures and their lexical counterparts, separately for correctly detected "new" (i.e., first presentation; see Figure 1A) and correctly recognized "old" stimuli (i.e., second presentation; see Figure 1B). All waveforms were characterized by a series of early deflections ending in a positivity measured from $230-300 \mathrm{msec}$ (P260), followed by an anterior maximal negativity (N350; $310-410 \mathrm{msec})$, and a later posterior negativity $(\mathrm{N} 450 ; 420-500 \mathrm{msec})$ with a more circumscribed distribution. A large positive deflection (P580; 510-700 msec) was maximal between $\mathrm{Cz}$ and $\mathrm{Pz}$. Separate ANOVAs of "old" versus "new" (across lags; see Table 2) and lag (old only), in combination with stimulus modality and electrode site, were performed on the averaged voltages.

As assessed by tests for simple effects, the stimulus modality $\times$ lag interaction for $\mathrm{N} 450[F(2,23)=4.5, p<$ $.03]$ was due to an effect of lag for words $[F(2,25)=6.5$, $p<.007]$ but not for pictures. Newman-Keuls tests showed that $\mathrm{N} 450$ for words was smaller at Lag 2 than at Lag 8 or Lag 32. It is possible that the larger N450 at longer word lags is related to the performance decrement

Table 1

Reaction Time Data

\begin{tabular}{|c|c|c|c|c|c|c|c|c|c|c|}
\hline \multirow[b]{3}{*}{ Stimuli } & \multicolumn{8}{|c|}{ Lag } & \multirow{2}{*}{\multicolumn{2}{|c|}{ Mean "Old" }} \\
\hline & \multicolumn{2}{|c|}{0 (“New') } & \multicolumn{2}{|c|}{2} & \multicolumn{2}{|c|}{8} & \multicolumn{2}{|c|}{32} & & \\
\hline & $R T$ & $S D$ & $R T$ & $S D$ & $R T$ & $S D$ & $R T$ & $S D$ & $R T$ & $S D$ \\
\hline Pictures & 690.7 & $135.3^{*}$ & 751.9 & 133.2 & 731.9 & 108.0 & 750.7 & 136.1 & 744.8 & 125.8 \\
\hline Words & 693.2 & $154.7^{*}$ & 751.1 & 113.8 & 747.8 & 113.3 & 796.9 & 147.5 & 765.3 & 124.8 \\
\hline
\end{tabular}

Note-Reaction times (RTs) are given in milliseconds. *Mean within-subject SD of RT. 
discussed above, since reactivation of the initial representation, due to memorial decay, might be necessary. Smith and Halgren (1989) have suggested that N400 (Kutas \& Hillyard, 1980) may reflect this kind of relatively automatic activation process (Graf \& Mandler, 1984). However, others have criticized the Smith and Halgren hypothesis (e.g., Rugg \& Nagy, 1989), and the current data do not provide definitive evidence on this issue.

As depicted in Figure 1 and as shown in Table 2, there was a significant main effect of stimulus modality for $\mathrm{N} 450$ and an interaction of stimulus modality with electrode site for both $\mathrm{N} 450$ and P260 due to the fact that, for both deflections, words produced greater amplitudes at the posterior electrodes than did pictures. Both interactions remained significant after scaling (see Table 2), indicating that the scalp distributions of these deflections differed for words and pictures.

The differences, however, could have been due to physical aspects that differed for words and pictures (exogenous) or cognitive differences in the way they were processed (endogenous). The font-modification control study allows preliminary judgments on this issue. The 5 additional subjects who saw word stimuli in both a large and a small font produced ERPs similar to those produced by the 15 subjects of the main experiment (see Figure 2). As can be seen, the positivity at about $260 \mathrm{msec}$ showed large differences as a function of font size. By contrast, although words showed much larger N350/N450 than did pictures, the font manipulation had no effect on these negativities.

Taken together, the present behavioral and ERP data suggest the tentative interpretation that different informationprocessing mechanisms were applied to word and picture representations of the same concept and that these took place in different regions of the brain.

\section{ERP Repetition Effects}

The ERP waveforms (Figure 1) associated with repeated presentations were more positive, relative to their first presentation counterparts, beginning as early as P260 and continuing through P580. As shown in Table 2, main effects of repetition ("old"/"new") were modulated by interactions between "old"/"new" and electrode site for all deflections, which remained significant for P260, N350, and N450 after scaling. Difference waveforms were computed by subtracting the "old" from the "new" ERPs, separately for pictures and words. To determine whether the difference waveform represented an effect only on P580, the scalp distribution of the N350 and N450 portions of the " "new" minus "old" waveforms were each compared with the P580 portion by normalizing the data to remove ampli-
A
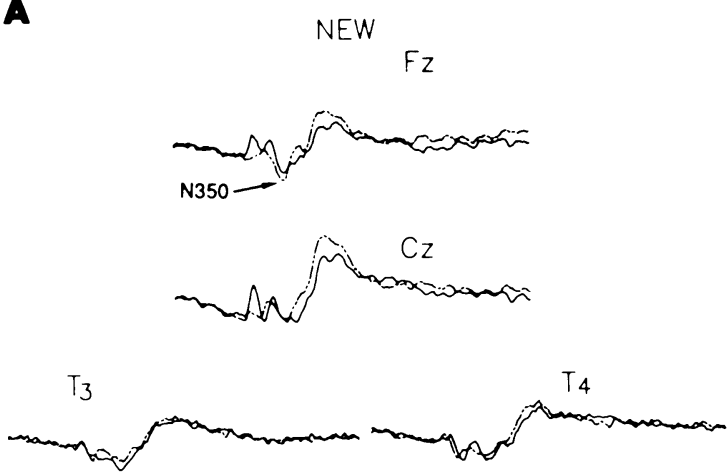

B
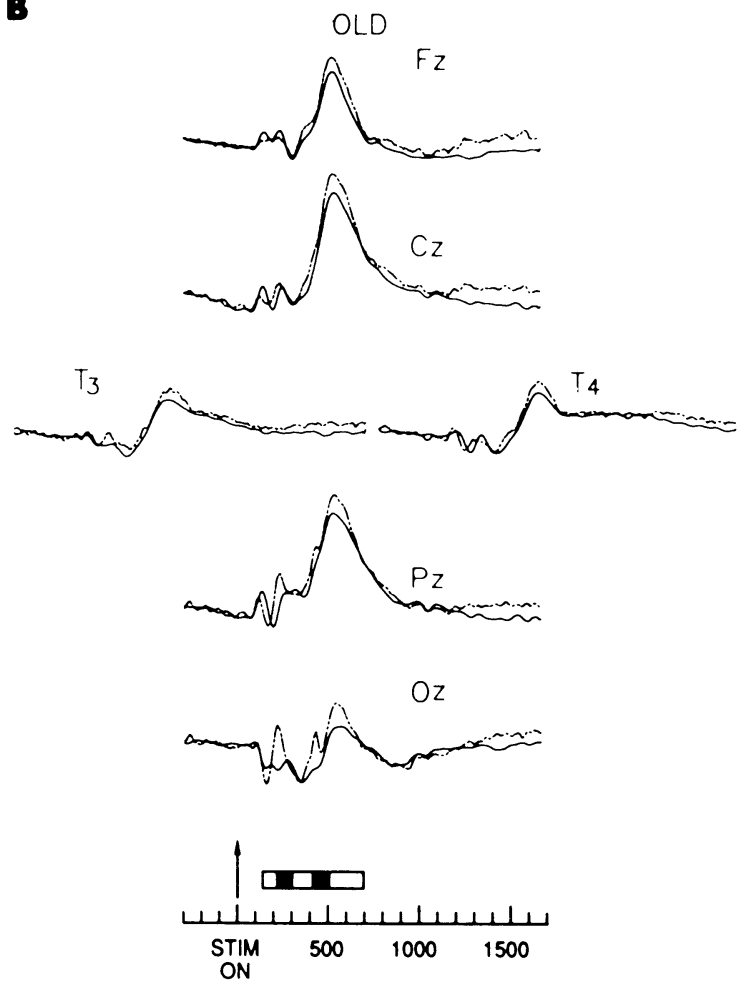

Figure 1. Grand mean event-related potentials (ERPs) averaged across subjects elicited by word and picture presentations of the same concepts. Data are depicted separately for correctly detected "new" (A) and "old" (B) stimuli. Arrows mark stimulus onset, with time lines every 100 msec. Black and white bands above the time line represent latency ranges used to obtain averaged amplitudes for each of the identified deflections. 
Table 2

Stimulus Modality $\times$ Old/New $\times$ Electrode ERP Results

\begin{tabular}{|c|c|c|c|c|}
\hline & $\mathrm{P} 260$ & N350 & $\mathrm{N} 450$ & P580 \\
\hline $\begin{array}{l}S \\
O \\
S E\end{array}$ & $\begin{array}{l}\text { o }>\mathrm{n} \dagger \\
\mathrm{w}<\mathrm{p}(\mathrm{Pz}, \mathrm{Oz}) \ddagger\end{array}$ & $\mathrm{o}<\mathrm{n}^{*}$ & $\begin{array}{l}\mathrm{w}>\mathrm{p} \dagger \\
0<\mathrm{n} \ddagger \\
\mathrm{w}>\mathrm{p}(\mathrm{Cz}, \mathrm{Pz}, \mathrm{Oz})^{*}\end{array}$ & $\begin{array}{l}\mathrm{w}<\mathrm{p} \\
\mathrm{o}>\mathrm{n}\end{array}$ \\
\hline $\begin{array}{l}\mathrm{OE} \\
\mathrm{SOE}\end{array}$ & $\begin{array}{l}\text { o > n }(\mathrm{Fz}, \mathrm{Cz}, \mathrm{Pz}) \S \\
\mathrm{OE}(\mathrm{p}) \ddagger\end{array}$ & $\mathrm{o}<\mathrm{n}(\mathrm{Fz}, \mathrm{Cz}) \S$ & $\mathrm{o}<\mathrm{n}(\mathrm{Fz}, \mathrm{Cz}, \mathrm{Pz}) \S$ & $\mathrm{o}>\mathrm{n}($ all $, \mathrm{Cz}, \mathrm{Pz}$ maxima $)$ \\
\hline
\end{tabular}

Scaled Electrode Interactions

SE $\quad \mathrm{w}<\mathrm{p}(\mathrm{Pz}, \mathrm{Oz}) \dagger \quad \mathrm{w}>\mathrm{p}(\mathrm{Oz}) \ddagger$

$\mathrm{OE} \quad \mathrm{n}<\mathrm{o}(\mathrm{Fz}, \mathrm{Cz}) \dagger \quad \mathrm{n}>\mathrm{o}(\mathrm{Fz}, \mathrm{Cz}) \S \quad \mathrm{n}>\mathrm{o}(\mathrm{Fz}, \mathrm{Oz})^{*}$

Note-Directions of effect(s) and all effects reaching or exceeding the .05 level of significance are listed. Key: $\mathrm{S}-\mathrm{w}=$ words, $\mathrm{p}=$ pictures; $\mathrm{O}-\mathrm{o}=$ old, $\mathrm{n}=$ new; $\mathrm{E}=$ electrode at $\mathrm{Fz}, \mathrm{Cz}, \mathrm{Pz}, \mathrm{Oz} .{ }^{*} p \leq .05$. $\dagger p \leq .01 . \quad \ddagger p \leq .001 . \quad \S p \leq .0001$.

tude differences between components. The scaled component $\times$ electrode site interactions indicated that the scalp distribution of the "old"/ "new" effect differed from P580 for both $\mathrm{N} 350[F(2,31)=37.8, p<.00005]$ and $\mathrm{N} 450$ $[F(2,30)=8.8, p<.0008]$, suggesting that at least two brain generators are differentially activated by repetition.

Because both N350 and N450 were most prominent for "new" items, we conclude that the early portion of the ERP repetition effect represents reduced negativity in the ERPs elicited by repeated stimuli, relative to their first presentation counterparts. The scalp distribution of the P580 portion of the difference waveform is consistent with a separate, but overlapping, enhancement of P300. Moreover, by manipulating task requirements, recent data also suggest that it is possible to selectively suppress either the negative (Rugg \& Nagy, 1989) or positive (Berman et al., 1990) aspects of the repetition effect.

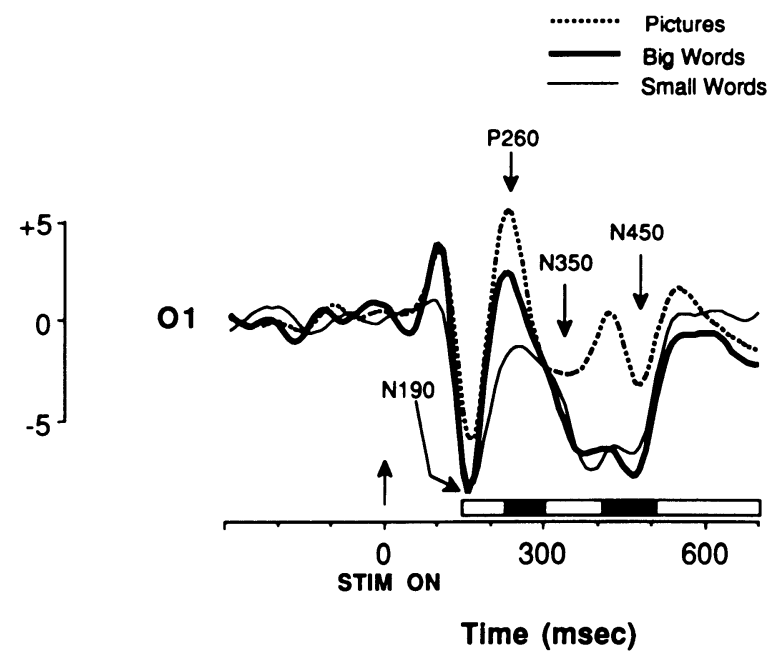

Figure 2. Grand mean ERPs elicited by correctly recognized "old" stimuli averaged across 5 additional subjects in the font-modification control study. Black and white bands represent the latency ranges used in Figure 1.

\section{REFERENCES}

Berman, S., Friedman, D., \& Cramer, M. (1990). A developmental study of event-related potentials to pictures and words during explicit and implicit memory. International Journal of Psychophysiology, 10, 191-197.

Berman, S., Friedman, D., Hamberger, M., \& Snodgrass, J. G. (1989). Developmental picture norms: Relationships between name agreement, familiarity, and visual complexity for child and adult ratings of two sets of line drawings. Behavior Research Methods, Instruments, \& Computers, 21, 371-382.

Donchin, E., \& Coles, M. G. H. (1988). Is the P300 component a manifestation of context updating? Behavioral \& Brain Sciences, 11, 357-374.

Friedman, D. (1990a). Cognitive event-related potential (ERP) components during continuous recognition memory for pictures. Psychophysiology, 27, 136-148.

FRIEDMAN, D. (1990b). ERPs during continuous recognition memory for words. Biological Psychology, 30, 61-87.

GraF, P., \& MaNDler, G. (1984). Activation makes words more accessible, but not necessarily more retrievable. Journal of Verbal Learning \& Verbal Behavior, 23, 553-568.

KuČERA, H., \& FrancIs, W. N. (1967). Computational analysis of present-day American English. Providence, RI: Brown University Press.

KUTAS, M., \& Hillyard, S. A. (1980). Reading senseless sentences: Brain potentials reflect semantic incongruity. Science, 207, 203-205.

McCarThy, G., \& Wood, C. C. (1985). Scalp distributions of eventrelated potentials: An ambiguity associated with analysis of variance models. Electroencephalography \& Clinical Neurophysiology, 62 , 203-208.

Nelson, D. L. (1979). Remembering pictures and words: Appearance, significance and name. In L. S. Cermak \& F. I. M. Craik (Eds.), Levels of processing in human memory. Hillsdale, NJ: Earlbaum.

Neville, H., Kutas, M., Chesney, G., \& Schmidt, A. L. (1986). Event-related brain potentials during initial encoding and recognition of congruous and incongruous words. Journal of Memory \& Language, 25, 75-92.

PaIvio, A. (1986). Mental representations: A dual coding approach. New York: Oxford.

RugG, M. D., \& NAGY, M. E. (1989). Event-related potentials and recognition memory for words. Electroencephalography \& Clinical Neurophysiology, 72, 395-406.

SMith, M. E., \& Halgren, E. (1989). Dissociation of recognition memory components following temporal lobe lesions. Journal of Experimental Psychology: Learning, Memory \& Cognition, 15, 50-60.

Waugh, N. C., \& Norman, D. A. (1965). Primary memory. Psychological Review, 72, 89-104.

(Manuscript received July 27, 1990.) 